\title{
The RLG Conspectus: Its Uses and Benefits
}

\section{Anthony W. Ferguson, Joan Grant, and}

\author{
Joel S. Rutstein
}

The Conspectus is an online subject inventory of library collections that facilitates cooperation and collaborative collection development. It also yields a number of practical internal benefits for participating libraries. This article explains why the Conspectus is a necessary and useful tool, describes its structure and operation, and illustrates how it can and is being used both to foster cooperation among North American libraries and to improve the management of resources within individual libraries.

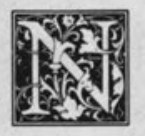

orth American research libraries, irrespective of size or budget, share at least two things: an insatiable desire to acquire a major share of the world's informational output and the lack of funds to accomplish this feat individually. Five years ago, thirty-four countries reported publishing more than 1,000 titles annually with a combined output of nearly 500,000 titles. Only two of the more than 100 libraries belonging to the Association of Research Libraries (ARL) added even 40 percent of that amount. Twenty-two managed to acquire 20 percent and eighty obtained less than 10 percent of that year's published output. ${ }^{1}$

Individually these libraries may lack the funds to acquire a year's title output. Collectively, however, they exhibit an enormous information gathering capability. Currently, ARL libraries spend a total of more than $\$ 350$ million per year on library materials. ${ }^{2}$ Although 80 percent of cataloged materials show some duplication, together the ARL libraries have the financial capability to collect nearly everything of value. ${ }^{3}$ If they do not, the problem lies in the inadequate stewardship of these resources.

Currently, the devalued dollar, the general downturn in the market, changes in tax laws, sluggish state economies, as well as federal budget deficit reductions are affecting libraries. Although these problems provide impetus for cooperative action, the end result has been individualized scrambles for survival and procrastination instead of collaborative resource development. While most of these problems are cyclical, their overall effect has led to short- rather than long-term solutions to the problem of inadequate coverage of the world's production of knowledge. A few of the largest libraries can maintain or advance their collecting standards but most

Anthony W. Ferguson is the Resources Group Director, Columbia University Libraries, New York, New York 10027. He currently chairs the RLG Collection Management and Development Subcommittee on the Conspectus and is a member of the ARL North American Collections Inventory Project Advisory Committee. Joan Grant is Director of Collection Management and Consortial Services, New York University Libraries, New York, New York 10012. Joel S. Rutstein is Assistant Director for Collection Services, Colorado State University Libraries, Fort Collins, Colorado 80523. All three are members of the RLG Collection Management and Development Committee, former members of its Steering Committee, and are trainers for the ARL North American Collections Inventory Project. The writing of this article was supported by a grant from the Council on Library Resources. 
are unable to keep up. Neither library nor academic administrators have pursued what is clearly in the national interest because the immediate problems facing each institution inhibit a long-term collective solution to the overall problem.

\section{"The Research Libraries Group Con- spectus supplies a framework that encourages selectors to think collabo- ratively and direct funds on targeted weaknesses rather than on unneeded duplication."'}

Fortunately, a new tool for collaborative behavior has emerged, enabling North American research libraries to provide better coverage and allowing individual libraries to determine what subjects are being adequately covered for research purposes elsewhere and what areas need additional coverage. This tool, the Research Libraries Group Conspectus, supplies a framework that encourages selectors to think collaboratively and direct funds on targeted weaknesses rather than on unneeded duplication. It can greatly facilitate stewardship of the nearly $\$ 350 \mathrm{mil}-$ lion spent this year by the largest research libraries. Use of the Conspectus can also lead to practical internal benefits as well.

The Conspectus was produced by those interested in pragmatic approaches to resource sharing. In 1974, collection development officers from the initial four Research Libraries Group institutions (Columbia, Harvard, Yale, New York Public) met to compare policy statements and find ways of coordinating collecting activities. In 1978, these four plus counterparts from Cornell, Chicago, Princeton, Stanford, and the Library of Congress (LC) heard a presentation by John Finzi from LC. Emphasizing that no one library could possibly acquire all of the world's publishing output, Finzi called for a national plan to distribute collecting responsibilities. What emerged from subsequent discussions was an inventory, the "Conspectus" of collecting activity upon which cooperative endeavors might be built. ${ }^{4}$

\section{STRUCTURE}

The Conspectus is essentially a survey indicating the depth of past collecting (existing collection intensity) and the current collecting depth (current collecting intensity). The Conspectus is structured on the more than 5,000 ranges of LC classification system numbers. Libraries indicate their past and current collecting practices by a 0 to 5 scheme of values for each call number range.

0 Out of scope

1 Minimal

2 Basic information

3 Instructional support

4 Research

5 Comprehensive

To clarify further what is being collected a range of language suffixes are added:

E for primarily English-language material

F for selected foreign-language material

W for wide selection of foreign-language material

$\mathrm{Y}$ for material primarily in one foreign language

For example, a library that in the past had collected at the instructional support level (3) but now was collecting at the research level (4) for the Spanish literature of Venezuela would report an existing collecting strength of $3 \mathrm{~F}$ or $\mathrm{Y}$ and a current collecting intensity of $4 \mathrm{~F}$ or $\mathrm{Y}$ for the LC classification PQ8530-8549.

The Conspectus is the matrix of collection depth indicators for all of the participating libraries. It can be used in either print or online computer versions. Currently, data for nearly all subjects have been collected from more than thirty libraries. Although the database is maintained by RLG, it contains information from both RLG and non-RLG libraries. The integrity of the inventory is overseen by the RLG Subcommittee on the Prospectus. To help libraries confirm the accuracy of their collecting intensity levels and compare their collections with others of the same reported intensity levels, verification studies and benchmark tests have been developed. 


\section{USE}

The success of the Conspectus as a resource-sharing tool and in other applications depends upon the interest and initiative of university administrators, scholars, and librarians who recognize the need to work cooperatively to ensure maximum access to scholarly information.

Use of the Conspectus has been hindered by the misunderstanding that it would magically produce cooperation in and of itself. This is not the case, nor have those deeply involved in its use made such claims. The Conspectus is a tool, a notepad that records past and present strengths and weaknesses. For library administrators who opt for the cooperative solution to "too many books and too few dollars," the Conspectus shows where the strong collections are and records agreements on who will collect what and at what level in the future. The Conspectus is an aid to cooperation but should not become the goal of this activity. The goal is to improve the stewardship of funds through better communication among those building collections to acquire, make accessible, and preserve the world's scholarly production for the national community.

The Conspectus is evolving as just such a tool. Experiments with its use are underway at the national, state, local, regional, and international levels. It has also proven to be a valuable management tool within individual libraries.

\section{"To provide protection for these 'en- dangered species,' the concept of 'primary collecting responsibility' (PCR) was established."}

\section{NATIONAL USES OF THE CONSPECTUS}

\section{Research Libraries Group}

The development of the Conspectus has enabled RLG to compare collections and collecting strengths among its members. As a result, certain subject areas have been identified as unique or not heavily collected by more than one or two libraries. To provide protection for these "endangered species," the concept of "primary collecting responsibility" (PCR) was established. Strong libraries in these specialized areas are identified and requested to assume responsibility for a PCR, commiting to continued collection to ensure that the strength will be maintained within the consortium. Given the strength of many RLG libraries, PCRs tend to be restricted in scope.

Recently, RLG has considered expanding PCRs to achieve even greater coverage by assigning them to two or more libraries with strong collections who would collaborate in major "bread and butter" areas of scholarship. A contrasting plan is also being developed to use PCRs during a time of severe economic downturn. In this scenario, "contingency PCRs" would be created which "would entail a pledge by each institution not to reduce its collection intensity for certain broad, designated subject areas below a 4-level (research level) in an economic emergency."

Conspectus use within RLG, however, has not been restricted to the acquisition of research material. It is also being used to share responsibility in cooperative preservation. RLG libraries recently agreed to focus on two levels of preservation activity: preserving high-use items identified locally and another set of items, irrespective of use, as a part of the consortial, national preservation effort. Using the Conspectus as a guide, a "national collection" consisting of one or more individual, strong research-level subject collections will be established. Libraries will accept a Primary Preservation Responsibility (PPR) for portions of their collections they want to preserve. Participation in the program is voluntary and will focus on microfilming published, paper-format materials with imprint dates between 1850 and 1950. Libraries outside RLG will also be encouraged to participate. RLG is seeking funds to defray the costs of this cooperative effort. ${ }^{6}$ RLG' $^{\prime}$ libraries have also recently agreed to annotate the Conspectus with collection specific preservation details, e.g., the time parameters of the ma- 
terial being preserved, source of funding, cooperative partners, method of preservation being employed, and number of volumes.

Several RLG libraries have also employed the Conspectus as an aid in seeking funds for converting card catalogs to machine-readable records. It has been used for similar purposes in a variety of shared cataloging discussions during the past few years.

\section{Association of Research Libraries}

Without doubt, the most successful and widespread use of the Conspectus at the national level (outside of RLG) is the ARL North American Collections Inventory Project (NCIP). ARL concluded that major research libraries must cooperate if they are to provide adequate support to their users. It examined various approaches and decided that the RLG Conspectus provided the best opportunity for success. A test of the instrument was conducted by a group of non-RLG libraries in Indiana. Its success led to the inauguration of NCIP, and the effort was expanded to include the full ARL membership. Recently it was announced that more than 80 percent of the 107 ARL member libraries were involved in or were considering Conspectus use.

\section{State and Regional Experiences}

Successful Conspectus-based resource sharing has been undertaken at the state and regional level. In both Colorado and Alaska statewide projects have included collection assessments modeled after the RLG Conspectus and standardized collection development policy statements for all participating libraries. The Colorado project, which began as a cooperative acquisitions program for unusual or expensive materials, initially included only research libraries. Now, however, the State Library has urged that the scope be broadened to include colleges, community colleges, and public libraries. The work in Alaska successfully modified the Conspectus for use by small libraries. Through their collection analyses the Alaskans have discovered unique caches of "Alaskania materials" in even the smallest public libraries.

The Alaska experience served as a model for regional effort conducted in the Pacific Northwest, sponsored by the Library and Information Resources for the Northwest (LIRN). They modified the RLG Conspectus to allow effective use by both small and large libraries. With the help of ARL, they also developed a regionwide training program. LIRN recently awarded grants supporting cooperative regional efforts based upon gathered data.

In New York State, legislation has made funding available to academic libraries participating in regional coordinated collection development plans. The plan for metropolitan New York encompasses the collections of two ARL/RLG libraries in addition to sixty academic libraries ranging from medium-sized to very small. Beginning this year, the Conspectus, as modified by LIRN, will be used as the group's collection analysis instrument. With it, these libraries, which are geographically close yet tremendously diverse in the nature and purpose of their collections, will have a common means of evaluating their collections and communicating their strengths and weaknesses.

In Indiana the universities of Purdue, Notre Dame, and Indiana were chosen by ARL to test the usefulness of the Conspectus and to analyze the work involved in completing the process. One result of that group's collaboration was establishing communication channels among the bibliographers of the three institutions. Their work has in turn coincided with a science Conspectus analysis done by the Committee on Institutional Cooperation (CIC), consisting of the Big Ten institutions and the University of Chicago. Indiana University participated in yet a third regional cooperative project with the University of Michigan. Those two institutions shared a Mellon grant to strengthen their collective Slavic resources. Conspectus collecting level indicators were used to coordinate collecting responsibility and avoid duplication. The Indiana example illustrates how the Conspectus provides a standard means of communication that cuts across 
organizational lines. Other regional NCIP efforts are underway in the Southeast and in California.

\section{Subject- and Language-Based Uses}

The Conspectus-generating process brings bibliographers together to discuss what each is doing. A subcommittee of the Seminar on the Acquisitions of LatinAmerican Library Materials, which had earlier distributed country/subject collecting assignments, is now examining the Conspectus to see how these responsibilities might be refined using the Conspectus. They have collected data for several non-RLG libraries as well. Several RLG subject- and language-based programs have used the Conspectus to further their program goals: East Asian libraries within RLG have made PCR assignments for obscure topics not collected by a single library at the research level and have employed the Conspectus to plan a cooperative preservation microfilming project. The RLG Law Program Committee is developing a verification study to ensure that definitions of collection depth indicators are uniformly interpreted. The RLG Music Program Committee has entered into a number of cooperative projects; including an attempt to ensure that needed journals were acquired by at least one member of the group. RLG Geology librarians who took part in a Conspectusrelated experiment (Conoco Project) are now revising the Conspectus to improve its use as a record-keeping tool for identifying both core and research material collections to be shared.

\section{INTERNATIONAL USES OF THE CONSPECTUS}

The National Library of Canada has adopted the Conspectus to promote resource sharing on a national scale based upon regional library groupings. Twentyfive of the twenty-nine Canadian Association of Research Libraries are committed to completing the Conspectus. An initial product will be a directory of special collections. A unique challenge has been a bilingual French-English version of the Conspectus and the manuals developed to help libraries take part in the process. ${ }^{7} \mathrm{~A}$ number of other countries have shown interest including Norway, Sweden, the Netherlands, and France. The Conspectus has also been completed in a number of British universities as part of a plan to improve resource sharing.

\section{INTERNAL BENEFITS OF USING OF THE RLG CONSPECTUS}

While originally developed as a tool of interlibrary cooperation, the Conspectus produces a number of very practical applications that make the time needed to complete it worthwhile. ${ }^{8}$ Library administrators are faced daily with choices not so much between right and wrong, but between many good directions that should be supported. The problem is allocating resources most effectively. This process is further complicated by staff members championing their priorities as the most important, and they are often emotionally as well as intellectually attached to them. Conflicts over priorities become battles over turf.

"The Conspectus can function as a
road map for individual libraries by
recording mutually agreed upon,
subject-specific statements."

Library administrators attempt to solve these conflicts between "good and good" by trying to get everyone to agree on the library's overall priorities, and then by applying what is learned to the specific case at hand. In recent years there has been a wide assortment of priority-setting programs: missions and goals programs, management by objective, long-range planning, strategic planning, the development of master plans, and five-year plans. Within this context the Conspectus can function as a road map for individual libraries by recording mutually agreed upon, subject-specific statements that provide guidance in the following situations: 
1. determining collecting priorities;

2. making the best use of a library's space;

3. selecting materials for preservation;

4. allocating and training materials selectors;

5. allocating materials budgets;

6. preparing for accreditation reviews;

7. improving faculty-library communication; and

8. finding outside funding support for library programs.

The Conspectus ties all the solutions to the collection or knowledge base, the heart of the library.

\section{Collecting Policies And Priorities}

Collection development policy statements are among the most frequently cited local uses of the Conspectus. A policy statement establishes the foundation for all library programs and can guide administrators and staff in the creation of specific policies and procedures. Some libraries have added a column to their internal version of the Conspectus to show their desired collecting level or the library's goals and plans for future collection building. Cornell, Columbia, and Brigham Young universities provide examples of libraries that have used the Conspectus as a foundation for their collection development policy statements.

While the Conspectus is arranged according to the LC classification system, narrative collection profiles for academic programs can easily be added. Because the Conspectus is in the RLIN database, departments can conduct online searches on all subjects of interest. This feature is endlessly flexible since any number of subject combinations can be examined.

\section{Space, Storage, Pruning Projects}

Research libraries usually store low-use books and journals rather than discard the material, since their mission is to preserve information that may be of future scholarly interest. The Conspectus can help identify materials for storage. For example, when the existing collection intensity is greater than the current collecting intensity in a particular collection, this indicates a diminishing local emphasis on the sub- ject and implies less use, a usual qualification for storage. The Conspectus also allows selectors to make more informed weeding decisions through their knowledge of similar or stronger collections elsewhere. By using the Conspectus, libraries can also work together to coordinate a centralized storage scheme. An internally mounted version of the Conspectus on a personal computer can be annotated with potential weeding or storage areas and serve as a master plan to guide many years of work. Without the Conspectus, such projects would be difficult to pursue.

\section{Staffing Allocation and Training}

Libraries today are challenged in allocating collecting responsibilities as inadequate staff and funding levels require leaner, more efficient operations. The Conspectus can better define reassignments by determining high/low growth areas, as well as areas requiring particular attention. Because of budget restraints, shifting program priorities, and preservation needs, collection assessment has grown as a major library priority. Collection evaluation is normally carried out by selectors and requires large blocks of time for an adequate assessment. By using the Conspectus, equitable divisions of responsibility are possible and will help avoid the problem of disproportionate assignments.

The Conspectus can also be used to establish processing staff allocations. Highgrowth areas, identified in the Conspectus, are targeted as cataloging priorities, which in turn affect the entire operational work flow.

The Conspectus is an ideal learning tool for newly assigned bibliographers. New selectors should have a guide to the collections for which they are responsible. The Conspectus is a ready-made learning device that instantly defines the collecting priorities. As every bibliographer knows, different levels of collecting require different selection methods. Minimal-level collecting would suggest the purchase of only basic works, some reference texts, and a representative journal sampling. Higher collecting levels obviously demand much more. Intensity code defini- 
tions developed for the Conspectus suggest what sorts of material should be purchased for a specific target level. A previously completed Conspectus describes what resources are already available. Time saved in becoming acquainted with the collection can be spent improving skills needed in the selector's collection development role.

\section{Fund Allocation/Fund Requests}

The Conspectus provides data useful in preparing annual or special budget proposals. Priorities for collection growth will be indicated by collection strengths that fall short of the level necessary to support current programs. To address such weaknesses the library may wish to request funds to support retrospective and current acquisitions. The Conspectus values can be cited and the level of support (or lack thereof) that they indicate can be explained as part of the justification for the budget proposal. Comparative information can also be useful in this regard. Wellrespected collections known to provide strong support to programs at other institutions may be located through the Conspectus. Their values may be compared to local values and cited in the budget request as a means of illustrating local deficiencies.

\section{"Colorado State University is consid- ering including portions of the Con- spectus in all academic department program reviews."}

Collecting levels values can also be used when allocating the local materials budget. The amount allocated to each subject is normally determined by weighing a combination of factors such as publishing output, average cost of materials, need for retrospective collection building, and the current collecting intensity that the library wishes to achieve. The Conspectus levels can establish the latter factor and ensure that budget allocation agrees with decisions about current collecting policy.

Libraries are sometimes caught between academic departments needing higher levels of support and a university administration that finds it difficult to allocate additional resources. The library can illustrate the need for additional resources by citing the current, inadequate strength of the relevant areas of the collection as represented in the Conspectus. Budget requests can then be based on the dollar amount necessary to bring the collection up to the desired level. Colorado State University is considering including portions of the Conspectus in all academic department program reviews, which are required every five years. If adopted, the Conspectus will be an official and integral feature of a university's program evaluation process for the first time.

\section{Accreditation}

Conspectus values can describe a library's collection to accrediting agencies. They are especially helpful in those cases where the standards are vague. The standards published by the National Council for Accreditation of Teacher Education, for example, require that, "The library provides resources that quantitatively and qualitatively support instruction, independent study, and research required for each advanced program. ${ }^{\prime \prime 9}$ Conspectus collecting levels address this issue exactly by indicating whether a collection simply defines and introduces a subject (level 2), or supports "undergraduate and most graduate instruction" (level 3), or "includes the major published source materials required for dissertations and independent research"' (level 4).

Accreditation teams will also be interested in comparing the library's resources to the support provided by similar institutions. Comparative data for this purpose can be extracted from the Conspectus for any subset. Profiles can be drawn to include libraries of comparable size, partners in resource sharing agreements, and geographically close neighbors. All of this data enhances the library's response to the accreditation team's queries.

\section{Faculty Relations}

Librarians work closely with faculty in developing and assessing collections. Of- 
ten it is difficult to find common ground when discussing library/faculty views on how a collection should or has been developed. The Conspectus is an excellent public relations tool in this regard, easily understood by both parties. Detailed topics such as "differential pricing," areas targeted for computer cataloging conversion, allocation formulas, and approval plans can all be placed within the context of the library's identifiable collection strengths and weaknesses. Sections of the Conspectus relevant to a faculty member's interests can inform discussion. The Conspectus can remove much of the political posturing that hinders cooperation between the faculty and the library.

The Conspectus can also improve relations with the faculty by helping student and faculty researchers refine or achieve their library research plans. For example, a researcher may discover that a certain collection within the library is too weak to support his/her work. With the aid of the Conspectus the subject specialist could suggest related collections where the library has strengths, without compromising the purpose and intent of the individual's project. Alternatively, the library can provide faculty members with Conspectus printouts of discipline strengths and weaknesses of other libraries for use in traveling to other collections. Without the Conspectus, this referral process would be less exact and more difficult.

\section{Grant Proposals}

Information gleaned from the Conspectus can be useful when preparing grant proposals. All proposals, whether or not they are collection related, include a narrative describing the strengths of the library's services and resources. The Conspectus provides considerable data for the latter; it can give the proposal writer a great deal of detail on collection strength. Its greatest value, however, is for proposals relating to library preservation, computer cataloging conversion, or other cataloging activities. Grant proposals for funds to process or preserve the collection are enhanced by demonstrable evidence that the collections will contribute significantly to the database of national re- sources. The New York Public Library has successfully used the Conspectus in this way.

\section{Preservation Priorities}

To establish priorities for local preservation programs many libraries have followed the example set by Yale and conducted collection condition surveys to gather data on paper quality, condition of bindings, and imprint dates. Without a tool like the Conspectus, however, it is difficult to keep track of the findings and what action should be taken. The Conspectus can also help determine what should receive priority attention under normal conditions. Collection areas where strong or emerging collection values converge with poor physical condition can be considered for priority preservation.

Libraries will also find the Conspectus useful in developing lists of collection areas to receive priority attention in case of an emergency, particularly water damage. Bibliographers can review the Conspectus for areas that are strong, unique, and/or irreplaceable, or that have physical features (e.g. glossy paper) that would require immediate attention. This information can be added as an appendix to the library's disaster recovery plan making it readily available to the recovery team when salvage procedures are put into operation.

\section{"During the ten years since its incep- tion, the Conspectus has gradually evolved into a major tool of commu- nication and cooperation between and within libraries."}

\section{CONCLUSION}

During the ten years since its inception, the Conspectus has gradually evolved into a major tool of communication and cooperation between and within libraries. Its value as a shared resource development aid is still evolving. It is in the interest of all academic administrators to increase the breadth and depth of the material acquired, cataloged, and pre- 
served by their research libraries. Clearly it is beyond the resources of any single institution to acquire even half of what is currently produced, let alone retrospectively collect centuries of scholarly output. The Conspectus is not in and of itself a plan to bring about the needed cooperation to achieve these ends, but it has proved to be both a useful planning document and an invaluable communication tool for pursuing these goals. It has facilitated our understanding of past and present collecting activities at national, regional, state/provincial, and international levels. It has also shown great potential within libraries for linking service and processing priorities to collecting priorities.

The question before many Conspectus users is how can they maintain autonomy while achieving the fruits of cooperation facilitated by the Conspectus. The key seems to be consciously deciding to focus on one's own strengths as reflected in the Conspectus, coordinating with other libraries to cover weaknesses, and constructing regional building blocks to contribute to the national goal of achieving educational excellence. Cooperation does not mean a loss of freedom. Instead collaborative collection building can result in increased freedom to emphasize what is important in an individual institution rather than use limited resources to collect broadly in areas of lesser interest.

By using the Conspectus as a tool of communication and coordination, re- search libraries can increase their efforts in a whole range of existing collaborative projects:

- Collecting and reproducing materials designed for internal distribution in such countries as the Soviet Union, China, or Third World nations lacking sophisticated systems of information distribution.

- Converting a century's worth of collecting and cataloging into computer readable records.

- Preserving the North American intellectual heritage: at least a third of all nineteenth-century printed materials require expensive microfilming or other preservation techniques.

- Overcoming the new challenges in computerized informational technology:

- Capturing and indexing huge bodies of scientific data produced by electronic sensing devices, fugitive electronic databases, and electronically exchanged scholarly papers.

- Collecting and cataloging subnational public and private printed documents, newspapers, popular materials, and local histories on a worldwide scale.

- Converting the actual texts of documents into an electronic format for inscription on laser discs or other highdensity modes of information storage. Collectively, North American research libraries have sufficient resources to attack many, if not all, of these and other projects. If they work together, success is likely.

\section{REFERENCES AND NOTES}

1. "Title Output: Principal Book-Producing Countries, 1980-82," in Bowker Annual 31st ed., (New York: Bowker, 1986) p.434-35.

2. ARL Statistics, 1984-85, (Washington, D.C.: Association for Research Libraries), p.17.

3. The amount of duplication can be discerned from studies of national bibliographic databases; $\mathrm{S}$. Michael Malinconico, "The National Bibliographic Network: A Patrician Pursuit," Library Journal 105:1791 (Sept. 15, 1980). More recently, an overlap study completed by seven large research libraries as a part of a RECON grant proposal discovered that, of several thousand title samples searched in both the OCLC and RLG databases, 19 percent were owned by only one library, 18 percent by more than two libraries, and 18 percent by three libraries. RLG "Summary of Overlap Results," (RLG, Sept. 12, 1985), unpublished. In the Illinois Statewide Library Computer System, it was determined that 51 percent of its 8.8 million titles were unique; Bernard G. Sloan, "Resource Sharing among Academic Libraries: The LCS Experience," Journal of Academic Librarianship 12:26-29 (Mar. 1986). 
4. Nancy E. Gwinn and Paul H. Mosher, "Coordinating Collection Development: The RLG Conspectus," College \& Research Libraries 44:128-40 (Mar. 1983). Another good historical overview can be found in David C. Stam, "Collaboration Collection Development: Progress, Problems, and Potential," IFLA Journal 12:9-19 (1986).

5. Ross Atkinson, memo to the RLG Collection Management and Development Committee, May 20, 1986.

6. "Cooperative Preservation Methodology Endorsed for RLG Members," (RLG) Operations Update 39:9-10 (Jan. 1987.).

7. Marianne Scott, "NCIP in Canada," Association of Research Libraries, Minutes of the 109th Membership Meeting, October 22-23, 1986, Washington, D.C., p.14-19.

8. The substance of this section was also given as a paper: Anthony W. Ferguson, "Internal Uses of the RLG Conspectus," Association of Research Libraries. Minutes of the 109th Meeting, October 22-23, 1986, Washington, D.C., p.21-25.

9. Standards for the Accreditation of Teacher Education (Washington, D.C.: National Council for Accreditation of Teacher Education, 1982), p.42. 